\title{
De la Facultad de Formación Docente en Ciencias a la Facultad de Humanidades y Ciencias
}

Leonor Chena ${ }^{(1)}$

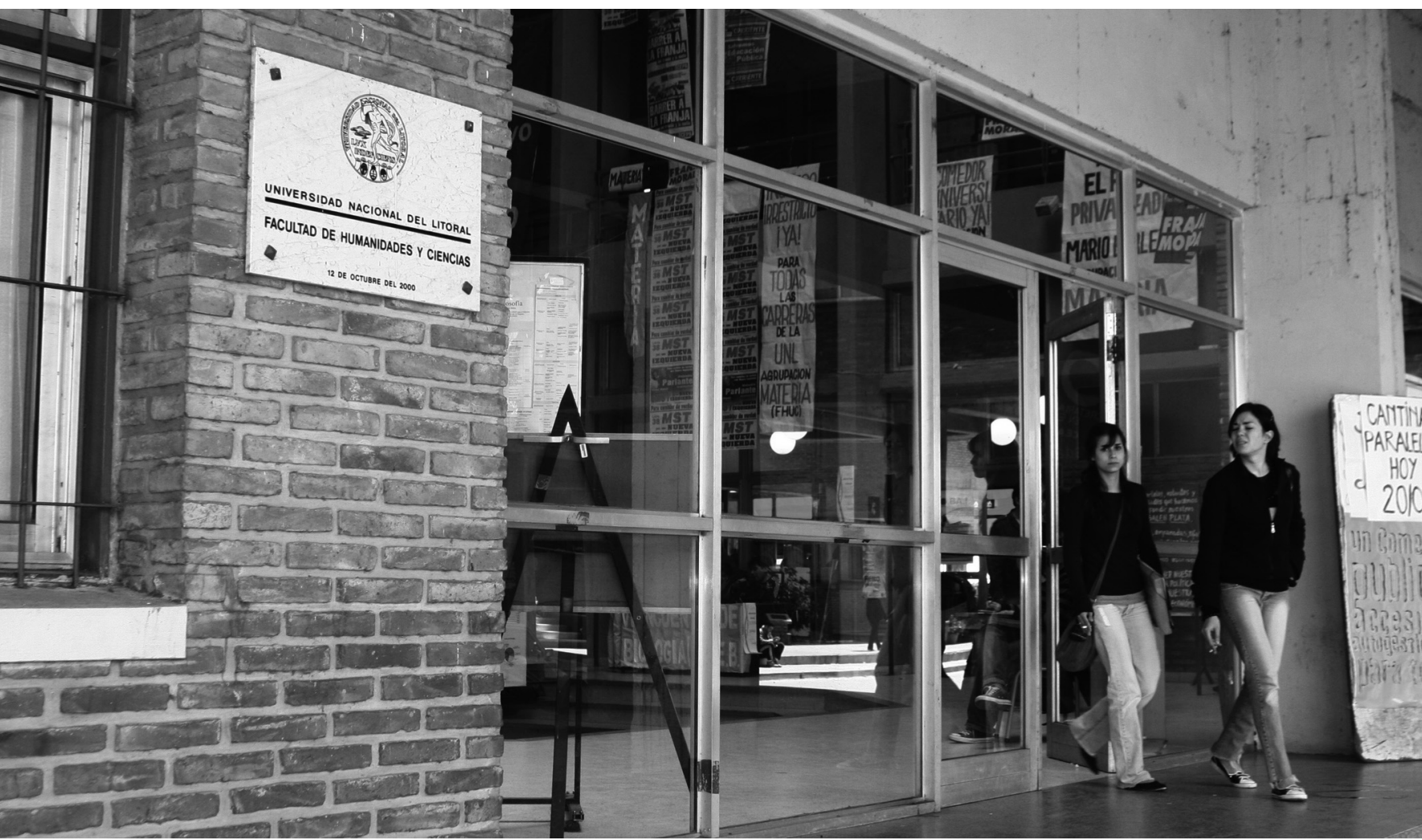

(1) Ex-Decana de la Facultad de Humanidades y Ciencias y actual Directora del Programa Proyectos Educativos Innovadores. 
El presente trabajo, pretende recuperar los principales documentos y argumentos que, desde el interior de la propia Facultad ayudaron a consensuar entre todos los estamentos el cambio de nombre $y$ el nuevo perfil de la institución y que sustentaron y consolidaron la concreción del proyecto.

La historia y los principios rectores de la Universidad Nacional del Litoral posibilitaron el desarrollo y crecimiento de sus Facultades, aun, en los periodos más difíciles. Un ejemplo de ello es la actual Facultad de Humanidades y Ciencias (FHUC).

El origen de la FHUC fue el Instituto del Profesorado creado en 1953, transformado en 1973 en Instituto del Profesorado Básico y luego en la Escuela Universitaria del Profesorado. Sobre su base, en 1987 se crea la Facultad de Formación Docente en Ciencias (FAFODOC) con cinco carreras de Profesorado.

El paso de Escuela Universitária a Facultad produjo un inmediato crecimiento académico; la incorporación de nuevas carreras de grado, el nacimiento del posgrado y la investigación, potenciaron las áreas disciplinares que se desarrollaban.

Las decisiones y tendencias que aparecen en el proceso del diseño curricular, indican que el nuevo perfil de la FAFODOC se construyó sobre la base de dos misiones igualmente prioritarias: 
- la producción de conocimientos en el campo de saber de las especialidades,

- el desarrollo de estudios para la formación docente.

De la afirmación anterior se desprende que la formación docente era, definitivamente, una de las ofertas de la FAFODOC, pero no la única. No obstante, de hecho, constituía un ámbito de formación y capacitación de profesores de nivel medio, contando con una reconocida trayectoria educativa en la región.

En tal sentido, ante la profunda transformación del sistema educativo argentino, no sólo se debió debatir el rol que les correspondía a las Universidades Nacionales en lo referente a la capacitación docente, sino que fue necesario replantearse la formación de profesores teniendo en cuenta las nuevas exigencias que los tiempos planteaban. Pero la formación de Profesores como carrera de grado debía también encuadrarse dentro de pautas específicas que regían dicha formación en el ámbito universitario.

De los retos que planteaba el siglo XXI se dedujo que la educación debía formar seres humanos capaces, entre otras cosas, de desenvolverse exitosamente en un mundo en rápido cambio formando individuos con criterios para un discernimiento autónomo con fundamentación ética, humanista, democrática y científica.

Es esa misión otorgada a la educación, el punto de partida y el insumo central para repensar la formación de docentes, insertos éstos en un sistema sometido a reconversión y cambios.

Cuestiones tales como: el diseño y análisis de propuestas curriculares, la incorporación de tecnología educativa como saber y como técnica, el diseño de proyectos y su evaluación, son algunas de las problemáticas en las que el docente hoy se encuentra involucrado y que requieren de un tratamiento que permita su conocimiento y comprensión.

Nada de ello es posible sin el debate y el consecuente aporte científico a estos campos temáticos, es decir, la búsqueda de propuestas de "buena enseñanza" disciplinar.

La institución educativa continuará existiendo, brindando respuestas a la necesidad de la sociedad de desarrollar individuos informados, autónomos, reflexivos, críticos, comprensivos, creadores y partícipes activos de la vida en 
comunidad. Capaces de continuar creciendo y aprendiendo a lo largo de toda su vida, tomando decisiones asumidas desde la libertad individual y la responsabilidad social y compartiendo la creación de la historia en lugar de sufrir un acontecer definido por unos pocos.

La educación, desde una mirada global, requiere ser repensada. Es necesario plantear líneas de reflexión para la acción, de modo de iniciar y concretar procesos de cambio profundo.

Esto induce a pensar que la Facultad percibe la necesidad de buscar el perfil institucional deseado para afrontar los cambios y transformaciones que le permitan adaptarse a los nuevos tiempos, a la complejidad de las transformaciones producidas en el medio en que se inserta, como al avance del conocimiento y modificaciones en el mundo del trabajo.

La ex Facultad, conformada en sus orígenes sólo por cinco carreras de Profesorado, oferta que posteriormente se amplía con la incorporación de cuatro licenciaturas, plantea como problema central la necesidad de repensarla. Reducir el pensamiento acerca de la reorganización de la Facultad sólo en términos de las carreras de grado implica el riesgo de hacerlo desde una mirada profesionalcita, por ello es necesario discutirla desde un lugar científico y disciplinar diferente: "la formación docente se desarrolla sobre la base y en estrecha vinculación con una sólida formación disciplinar".

Tal cuestión: formación docente-formación disciplinar conlleva proponer algunos criterios generales para elaborar un nuevo modelo organizativo.

Si bien una parte de estos problemas debe resolverse en la esfera estrictamente académica ( $\mathrm{Vg}$. decisión sobre carreras y otras ofertas, rediseño curricular, formación externa de docentes, etc.), también el modelo organizativo que se adopte puede influir en forma decisiva en la orientación que se imprima a las futuras actividades de la Facultad. Por lo tanto, el Modelo que se esboza, procura cumplir ese papel facilitador de una oferta académica de alta calidad e impacto. En este sentido, el modelo organizativo se erige en el instrumento central de la estrategia de desarrollo institucional.

En 1995 la Universidad a través de sus cuerpos orgánicos dispuso la integración del Instituto Superior de Música (dependiente del Rectorado) a la Facultad y la formulación de un diseño institucional. 
La integración de ambas unidades académicas contempló la necesidad de preservar identidades institucionales fuertemente consolidadas. Aparecen así dos cuestiones las relativas a la:

- gestión operativa-administrativa y a la

- gestión académica.

Se adoptó una estrategia de abordaje integral y sistemática.

Decíamos que la formación de profesores dejó de ser el único eje en torno del cual la Facultad crecía. Su nombre tampoco respondía a lo que la institución producía académica y cientificamente y esto fue generando que su comunidad no se sintiera identificada bajo tal denominación.

Esto conduce a la idea de que la denominación Facultad de Formación Docente en Ciencias, marcaba una identidad que aparecía desvirtuada no sólo por su oferta académica sino por las misiones que imaginaba su comunidad. Fue así que se tornó necesario considerar una denominación alternativa, lo que implicó pensar en una nueva Facultad y en su perfil.

Esto significó distinguir las misiones que su comunidad educativa acordó y que surgieron de la cultura disciplinar que le era propia.

En tal sentido se tuvo en cuenta que la presencia de estudios de literatura, lenguas clásicas, historia y filosofía marca un claro campo de pertenencia a las Humanidades, que sin serlo en su totalidad, permitiría inscribir estudios del hombre, sus producciones y sus entornos contextualizados a lo largo del desarrollo de la humanidad.

Asimismo, contenía un conjunto de disciplinas que, si bien correspondían a áreas diferentes de la actividad científica, caían todas bajo el denominador común de "ciencias". Es decir, la presencia de tales disciplinas indicaba que la producción de conocimientos que se pretendía desarrollar y fortalecer, era en torno a problemas de la sociedad y de la cultura.

Resulta menos lineal la argumentación cuando se pensó en Matemática y Biodiversidad, disciplinas que también componían la oferta de la institución. No obstante, corresponde decir en primera instancia que contener a ambas es reconocer la historia y el origen de la Facultad.

Es posible sostener también que ambas se enmarcan en estudios que dan cuenta de lo social y lo cultural. En ese sentido es que se pensó que la forma- 
ción socio-crítica del hombre requiere tanto de saberes socio-históricos como así también de estudios matemáticos y ambientales.

La Educación Matemática, que se pretendía desarrollar y fortalecer, daba cuenta específicamente de los problemas de la comprensión en el campo, no solamente en lo que respecta a la formación docente, sino entendiendo en la propia especialidad.

La Licenciatura en Biodiversidad se estructura teniendo en cuenta dos ejes: el evolutivo y el ecológico. El primero porque es fundamental conocer los procesos biológicos desde este enfoque ya que para resolver los problemas actuales tenemos que conocer en profundidad los aspectos inherentes a la naturaleza y la evolución de los seres vivos, comprender la diversificación de las interacciones entre las poblaciones y sus respectivos ambientes, los procesos de radiaciones adaptativas a nuevos ambientes, ajustes a cambios ambientales y el origen de nuevas formas de explotar hábitos existentes.

La elección del eje ecológico que a su vez es interdependiente del evolutivo resulta obvia en un mundo que puede contener tan vasta biodiversidad y por ende es necesario tratar de comprender las posibles interacciones entre los organismos y su ambiente, la distribución y abundancia de los seres vivos que difiere tanto histórica como geográficamente y comprender las funciones de la diversidad biológica.

Es decir, el currículum de la licenciatura en Biodiversidad se propone el conocimiento de la composición, distribución, estructura y funciones de la biodiversidad, su origen, conocer las medidas que deben tomarse para conservar la diversidad genética y la de ecosistemas, así como la restauración y remediación de sistemas perturbados.

Se incluyen además disciplinas que integran la formación humanística y la científico-tecnológica que permita una amplia comprensión de las relaciones entre las Humanidades, las ciencias y la tecnología como producciones humanas y respuestas a necesidades sociales, porque se considera que las medidas inherentes a la conservación y manejo de la biodiversidad deben planificarse y ejecutarse teniendo en cuenta no sólo criterios científicos sino también sociales.

Entre las distintas circunstancias a analizar en relación al aumento de la tasa de disminución de biodiversidad se deben incluir los cambios en la organi- 
zación social, el incremento de la población humana y demandas del desarrollo económico. En este sentido las medidas inherentes a la conservación de la biodiversidad y el uso de la tierra en su concepción más amplia deben planificarse y ejecutarse teniendo en cuenta no sólo criterios ecológicos sino también sociopolíticos y económicos. La formación humanística de un Licenciado en Biodiversidad aparecía como fundamental ya que esto le permitirá dimensionar las implicancias éticas y sociales en relación a la problemática del medio ambiente. Esto implica la integración de la formación humanística y la científica-tecnológica que permita una amplia comprensión de las relaciones entre las humanidades y la tecnología como producciones humanas y respuestas a necesidades sociales.

Además, contener, recuperar, desarrollar y jerarquizar las áreas del saber contenidas en el campo de las Humanidades, implicaba ocupar un lugar de vacancia reconocido en nuestra Universidad y significaba pensar en el marco de un proyecto estratégico de desarrollo.

En el campo de las ciencias sociales ubicamos en la FAFODOC a la Geografía, definida tradicionalmente como "estudio del espacio". Las Ciencias Sociales han descubierto el valor inherente de una categoría espacial mucho más compleja que aquella de corte funcionalista que dominaba los años setenta, recuperando sólidas tradiciones culturales, por las cuales aparece el "lugar" como una categoría esencial para comprender el funcionamiento de las sociedades actuales. El espacio no constituye algo substancial o continente, sino que representa "una determinación constitutiva e inseparable de las cosas y los procesos físicos mismos", no es solamente un producto social, sino también a su vez, condición y medio del proceso de producción y reproducción social. No resulta exclusivamente el reflejo mecánico de una sociedad o de un modo de producción en un momento dado, sino que representa el resultado de la acumulación histórica de trabajo humano y de la superposición diacrónica y sincrónica de varios modos de producción y aún de la evolución o de las diferentes etapas del propio modo de producción dominante en la actualidad.

La Historia comparte con la Geografía el ámbito de las ciencias sociales, pero al mismo tiempo se reconoce como una disciplina humanística, posición sostenida especialmente desde los debates llevados a cabo por Dilthey, Rickert y Windelband. 
La Historia como relato centrado en el hombre y los acontecimientos se inscribió desde siempre entre las Humanidades, junto a la Filosofía y las Letras. En su carácter narrativo residió y reside la esencia de esta pertenencia.

En el siglo XIX, la búsqueda de un estatuto científico para los saberes "sociales" la aproximó a las "primeras" ciencias sociales: Sociología, Economía, apartándola, en cierto sentido, de la primera orientación.

La convergencia de estas dos tradiciones refleja la notable ampliación del campo de la historia en los últimos veinte años, tipificado por el auge de la historia social, donde caben como objeto de estudio los cambios de la psique humana hasta los símbolos y los rituales. La historia narrativa toma prestado el espíritu y el planteamiento teórico de las mismas ciencias sociales que la habían empujado a un segundo plano, complementando -en vez de suplantarel análisis de estructuras y tendencias socioeconómicas. En resumen, la Historia de finales de siglo XX registra una doble pertenencia -al grupo de las Humanidades y al de las Ciencias Sociales.

En el campo de las Letras se engloban diversas diciplinas. La estructura curricular actual de la carrera en la FAFODOC reconoce tres grandes áreas: estudios literarios, lingüística y semiótica. Las últimas dos mencionadas se reconocen como ámbitos de cientificidad, debatiéndose el primero entre las pretensiones de cientificidad y otros paradigmas del saber, tal como el filosófico en sentido general, el estético, etc.

Hay un modo clásico de reconocer a la lingüística como ciencia: en primer lugar, pudo darse un objeto de estudio (que se modificará según cuál sea la perspectiva de investigación que se asuma); pudo establecer metodologías propias para tratar ese objeto (o los que se constituyan a partir de los marcos teóricos asumidos); pudo establecer sistemas y modelos teóricos que expliquen cuestiones inherentes a ese objeto.

Siguiendo a Jackobson se puede agregar que tiene un léxico especializado o, en términos de Hempel, un sistema de términos técnicos y teóricos que categorizan regiones del objeto que trascienden la esfera de lo empírico. Por otra parte, ese objeto tiene características particulares: es homogéneo y es eternalizable, en el sentido de que se vuelve visible y observable para los investigadores a través de las categorías de análisis. 
Por otra parte la lingüística tiene establecido un sistema institucional de validación o control sobre el conocimiento que se produce. El ideal de este control público del conocimiento producido, como el sistema de publicaciones, congresos, etc., permite la existencia de un cuerpo de conocimientos bien establecidos y evaluados a partir del cual es posible producir nuevos conocimientos. Por otra parte la lingüística es una actividad de producción de conocimiento en el sentido de que existen esfuerzos permanentes por renovar el cuerpo de conocimientos establecidos. Estas características hacen de la lingüística una ciencia empírica que ha sido modelo (nos referimos al paradigma estructuralista) para las demás Ciencias Sociales.

Desde el punto de vista de la producción del conocimiento, la lingüística es una actividad donde existen normas de producción y de acción establecidas dentro de la ciencia. Estas normas incluyen un sistema de ingreso (la formación como aprendiz de ciencia) y Reconocimiento como miembro de la disciplina (sistemas formales, doctorados y publicaciones; relaciones académicas y reconocimiento de pares), así como un modo de producir y someter a control crítico. Hoy la lingüística es modelo para el desarrollo de otros campos del saber -las Ciencias Cognitivas, por ejemplo-. Por otra parte constituye, con otras disciplinas, espacios de investigación interdisciplinaria: Psicolingüística, Sociolingüística, Neurolingüística, Análisis del Discurso, entre otros.

Íntimamente vinculada al desarrollo de los estudios literarios, las lenguas clásicas -Griego y Latín forman parte del currículo de varias carreras de la actual FAFODOC- y de las teorizaciones sobre el lenguaje, en particular con la semántica y la retórica -y tradicionalmente también con la gramática- se halla la filosofía. El Trivium de los estudios universitarios tradicionales es un ejemplo de la vinculación estrecha de estos saberes. La denominación de "Humanidades" ha englobado desde antaño a estas disciplinas.

Comenzaba a desarrollarse en la FAFODOC la carrera de pre-grado: Diplomatura en Humanidades, que conformará el primer ciclo de una Licenciatura en Filosofía (implementado poco después en la Facultad).

Retrospectivamente, la Academia de Platón y sus continuadores, así como las diversas escuelas que surgieron desde la Antigüedad Griega, fueron las primeras experiencias pedagógicas institucionales en donde se originaron, crecieron y desarrollaron las ciencias. Entonces, la relación del pensamiento 
universal con las diversas representaciones teóricas no sólo era estrecha, sino necesaria. Resultaría harto excesivo mostrar en la historia ejemplos de comunidades generadoras de un fértil trabajo científico y a la vez robustas productoras de pensamiento.

La filosofía nos permite hoy una introducción a preguntas generales, una habituación a consideraciones universales que conciernen al hombre, a la sociedad, al saber en toda su extensión. Favorece además, un espacio de discusión acerca de la relación de la ciencia con un saber general, el filosófico. Asimismo, la tradición filosófica posibilita el fortalecimiento de un ámbito de pensamiento en el que aquella se recree libremente, que permita crecer esa relación que Kant sustenta como estrecha, y posibilitadora de la manifestación de la verdad, como emergente del ejercicio libre de la facultad del pensar (EI Conflicto de las Facultades), y que en tal sentido, exige y promueve el desarrollo específico de capacidades intelectuales y prácticas: de conciencia, de problematización, de reflexión, de crítica, de respeto a formulaciones diversas.

La incorporación de las carreras de Humanidades y de Filosofía a la Facultad, favoreció, sin duda, un espacio de discusión acerca de la relación entre ciencia y tecnología, arte y filosofía. Esto provocó que interrogaciones presuntamente marginales en la formación disciplinar se prosigan en su generalidad permitiendo abrir un campo de investigación creativa. De modo que, la inserción de la filosofía en la institución no se hace desde un espacio ajeno y desvinculado de las actuales prácticas científicas y artísticas de la UNL, sino desde una perspectiva de enriquecedora integración.

En definitiva y como traté de explicitar en párrafos anteriores, definir el perfil y la nueva denominación de la Facultad de Formación Docente en Ciencias no fue una tarea sencilla dada la complejidad que implicaba un proceso de transformación institucional.

Entonces en tal sentido resultó de sumo interés plantear el cambio de nombre a través de la formulación "Facultad de Humanidades y Ciencias", que significa una postulación original y sugiere caminos que no deberían desdeñarse.

Se pensó que no se debía temer desde las Humanidades, una eventual reducción al campo científico-natural ("empirista") que pudiese significar la presencia conjunta, e incluso algún grado de integración, de científicos y académicos de estas áreas diversas. Por el contrario, no debía desdeñarse la influencia 
opuesta, el aporte que puede realizarse desde el campo social y humanístico al ámbito científico-natural (basta mencionar el campo de la ética, en su relación con la ética aplicada, por ejemplo). De todos modos, de lo que se trataría es de la riqueza de la interrelación y no del privilegio de uno sobre otro.

Al respecto conviene mencionar algunos ejemplos que apoyan o fundamentan la propuesta: "recordemos que en Alemania hay por ejemplo, Universidades Tecnológicas donde se enseña filosofía y hasta en el nombre se encuentra "Facultad de Ingeniería y Filosofía". Es decir históricamente se dieron allí situaciones de esta índole. También recordemos que un filósofo de la importancia e influencia de Wittgenstein era ingeniero mecánico.

Por otra parte, resulta de interés recordar algunas clasificaciones de la ciencia, que si bien sabemos que es un tema polémico y con una discusión no cerrada, también fueron elementos que ayudaron a la fundamentación del nuevo nombre de la Facultad. Por ejemplo la que hace Gadamer en Ciencias Naturales (física, química, biología, etc.), ciencias sociales (economía, sociología, antropología, historia, etc.) y ciencias humanas (filosofía, filología clásica, etc.), apuntando a mostrar las vinculaciones y diferencias entre ellas. Es decir, la interrelación -y en este sentido, la posible complementación metodológica- no tiene por qué significar la pérdida de autonomía ni mucho menos, sino la posibilidad de enriquecimiento mutuo, que implica un desafío no exento de originalidad que podría plantearse y aceptarse sin temor.

Fue así como transcurrió el complejo pero fértil momento -que tal vez con el correr del tiempo se considere como histórico-, de discusión, propuesta y consolidación de nuestra actual Facultad de Humanidades y Ciencias de la UNL. 